\title{
Separate influence of dietary carbohydrate and fibre on the metabolic control in diabetes
}

\author{
G. Riccardi, A. Rivellese, D. Pacioni, S. Genovese, P. Mastranzo and M. Mancini \\ Institute of Internal Medicine and Metabolic Disease, Second Medical School, University of Naples, Naples, Italy
}

\begin{abstract}
Summary. To clarify the separate influences of digestible carbohydrate and of dietary fibre on blood glucose control and serum lipoproteins, 14 diabetic patients (six Type 1 and eight Type 2) were submitted to three weight-maintaining diets for 10 days each: (1) low carbohydrate/low fibre diet with $42 \%$ carbohydrate and $20 \mathrm{~g}$ fibre; (2) high carbohydrate/low fibre diet (carbohydrate 53\%, fibre $16 \mathrm{~g}$ ); (3) high carbohydrate/ high fibre diet (carbohydrate $53 \%$, fibre $54 \mathrm{~g}$ ). In comparison with the low carbohydrate/low fibre diet, the 2-h post-prandial blood glucose and the daily blood glucose profile decreased significantly on the high carbohydrate/high fibre diet, without significant changes during the high carbohydrate/low fibre diet. The diet-induced modifications of blood glucose control were similar in both types of diabetic patients (twoway analysis of variance: $\mathrm{F}=5.86, p<0.02$ for dietary treatment and $F=2.09$, NS for type of diabetes). Total and lowdensity lipoprotein cholesterol were also decreased after the high carbohydrate/high fibre diet in comparison with the low
\end{abstract}

carbohydrate/low fibre diet $(p<0.001$ for both), while they were not significantly modified after the high carbohydrate/ low fibre diet. Again the modifications of low density lipoprotein cholesterol induced by diet were similar in both types of diabetic patients $(\mathrm{F}=10.02, p<0.005$ for dietary treatment and $\mathrm{F}=0.14$ for type of diabetes, NS). High-density lipoprotein cholesterol was lower after the two test diets than after the low carbohydrate/low fibre diet. However statistical significance was found only for the high carbohydrate/high fibre $\operatorname{diet}(p<0.005)$. In conclusion: (1) a simple increase of digestible carbohydrate without a parallel increase of dietary fibre does not help in improving the metabolic control of diabetic patients; (2) the hypoglycaemic and hypolipidaemic effects of high carbohydrate/high-fibre diets are due principally to dietary fibre.

Key words: Diet, Type 1 and 2 diabetes, blood lipids, lipoproteins, dietary fibre, dietary carbohydrate, blood glucose.
The American Diabetes Association Committee on Food and Nutrition recommends that most diabetic patients, especially those with Type 1 (insulin-dependent) diabetes, use a diet containing $50 \%-60 \%$ of the caloric intake in the form of carbohydrate $(\mathrm{CHO})$, limiting the consumption of fats below $30 \%$ of the total energy intake [1]. Similar recommendations have been issued by other diabetic associations $[2,3]$. This new strategy was adopted with the aims of reducing the rate of atherogenesis and improving blood glucose control in patients with diabetes.

However, criticisms have been raised against these dietary recommendations owing to the lack of sound experimental data on which to establish the new strategy [4]. The available information on the metabolic effects of high $\mathrm{CHO}$ diets is controversial [5-8].

Many confounding variables obscure the influence of $\mathrm{CHO}$ on lipids and carbohydrate metabolism. In many studies, high $\mathrm{CHO}$ diets were used which, at the same time, were high in vegetable fibre. We have demonstrated that a high fibre diet is able, per se, to improve blood glucose control and to lower low-density lipoprotein cholesterol in diabetic patients $[9,10]$. In other studies diets were not physiological, both in the use of nonnatural foods (liquid formula diet) and in the choice of a very high $\mathrm{CHO}$ content $(75 \%-85 \%)[5,6]$.

This study was therefore undertaken to evaluate the effects of a simple increase of dietary CHO on blood glucose metabolism and on serum lipoproteins, by comparison with a parallel increase of both dietary $\mathrm{CHO}$ and fibre. All diets were composed of natural foodstuffs and were tried in patients with both types of diabetes.

\section{Subjects and methods}

\section{Subjects}

Eight Type 2 (non-insulin-dependent) and six Type 1 (insulin-dependent) diabetic patients participated in the study after giving informed consent. The mean \pm SD age was $47 \pm 5$ and $33 \pm 13$ years, respectively. The average body mass index was $28 \pm 5$ and $22 \pm 4 \mathrm{~kg} / \mathrm{m}^{2}$, and the duration of diabetes was $7 \pm 2$ and $12 \pm 6$ years. 
Table 1. Composition of the $2200 \mathrm{kcal}$ diet

\begin{tabular}{|c|c|c|c|c|c|c|}
\hline & \multicolumn{2}{|c|}{ Low $\mathrm{CHO} /$ low fibre } & \multicolumn{2}{|c|}{ High $\mathrm{CHO} /$ low fibre } & \multicolumn{2}{|c|}{ High $\mathrm{CHO} /$ high fibre } \\
\hline Protein & 121 & 21 & 98 & 17 & 98 & 17 \\
\hline \multicolumn{7}{|l|}{ Fat } \\
\hline Total & 93 & 37 & 76 & 30 & 74 & 30 \\
\hline Saturated & 26 & & 17 & & 18 & \\
\hline Cholesterol & $<0.250$ & & $<0.250$ & & $<0.250$ & \\
\hline \multicolumn{7}{|l|}{ Carbohydrate } \\
\hline Total & 252 & 42 & 318 & 53 & 321 & 53 \\
\hline Simple & 108 & & 111 & & 112 & \\
\hline Complex & 144 & & 207 & & 209 & \\
\hline Plant fibre & 20 & & 16 & & 54 & \\
\hline
\end{tabular}

${ }^{\text {a }}$ Contribution to total (100\%) available energy content of diet

Table 2. A daily scheme of the fibre-rich diet

\begin{tabular}{|c|c|c|c|}
\hline \multicolumn{2}{|l|}{ Breakfast } & \multicolumn{2}{|l|}{ Snack } \\
\hline Skimmed milk & $(100 \mathrm{~g})$ & Apple & $(150 \mathrm{~g})$ \\
\hline Wholemeal bread & $(40 \mathrm{~g})$ & & \\
\hline \multirow[t]{2}{*}{ Cottage-cheese } & $(30 \mathrm{~g})$ & Dinner & \\
\hline & & Butter beans & $(80 \mathrm{~g})$ \\
\hline Lunch & & Sole fish & $(100 \mathrm{~g})$ \\
\hline Spaghetti & $(70 \mathrm{~g})$ & Mushrooms & $(300 \mathrm{~g})$ \\
\hline Beef (lean) & $(100 \mathrm{~g})$ & Wholemeal bread & $(100 \mathrm{~g})$ \\
\hline Artichokes & $(300 \mathrm{~g})$ & Strawberries & $(250 \mathrm{~g})$ \\
\hline Wholemeal bread & $(80 \mathrm{~g})$ & & \\
\hline \multirow[t]{2}{*}{ Orange } & $(200 \mathrm{~g})$ & Snack & \\
\hline & & Apple & $(150 \mathrm{~g})$ \\
\hline
\end{tabular}

$50 \mathrm{~g}$ olive oil was consumed daily

Seven of the Type 2 diabetic patients were treated with glibenclamide $(5-20 \mathrm{mg})$, while the remaining patient was on diet alone. The dosage of hypoglycaemic drugs was kept constant throughout the experiment.

All the Type 1 diabetic patients were treated with two daily injections of insulin (isophane + soluble) before breakfast and dinner. The insulin dosage was changed ( \pm 4 units/day) if severe hypoglycaemic attacks or marked glycosuria ( $>5 \mathrm{~g} /$ day) occurred, but the time of insulin therapy and the type of insulin used were always the same.

\section{Diets}

Patients were admitted to a metabolic ward and given three weightmaintaining diets in a random order and for consecutive periods of 10 days. The diets were composed of natural food stuffs easily available at any food-shop. Their composition is outlined in Table 1: (1) a low $\mathrm{CHO}(42 \%) /$ low fibre $(20 \mathrm{~g})$ diet which resembled a traditional diet for diabetic patients used in many countries [11]; (2) a high $\mathrm{CHO} /$ low fibre diet with an increased proportion of $\mathrm{CHO}(53 \%)$ and a low amount of fibre as in the previous diet (16 g); (3) a high CHO/high fibre diet with increased amounts of both CHO $(53 \%)$ and fibre $(54 \mathrm{~g})$.

The three diets had similar amounts of soluble CHO and an identical polyunsatured/saturated fat ratio. They were distributed between the two main meals (lunch and dinner), a light breakfast and three snacks. Each meal contained a fixed proportion of nutrients and fibre and was consumed at the same time every day.

The vegetable fibre in the high $\mathrm{CHO} /$ high fibre diet was provided mainly by leguminous sources $(45 \%)$ and by different types of vegetables (37\%), the remaining part being wholemeal bread (12\%) and fruit $(6 \%)$. One of the various daily menus of the fibre-rich diet is given in Table 2. Calories, nutrients and fibres were calculated from tables of food composition [12] prepared using the Southgate method for the analysis of dietary fibre [13].

\section{Experimental procedure}

During each experiment, patients were weighed daily. At the end of each dietary period blood glucose levels were measured [14] on samples taken in the fasting state, before lunch, before dinner and $2 \mathrm{~h}$ after lunch and dinner. On the same day a fasting serum specimen was taken for the analysis of cholesterol [15] and triglycerides [16] in total serum and in the major lipoprotein classes, which were separated by preparative ultracentrifugation [17].

\section{Statistical analysis}

The results of the low $\mathrm{CHO} /$ low fibre diet were compared with those of each of the two remaining diets. Statistical significance was tested by Student's paired t-test [18].

A two-way analysis of variance [18] was utilized to test simultaneously the hypothesis that changing the type of diet from a low $\mathrm{CHO}$ / low fibre diet to either a high $\mathrm{CHO} /$ high fibre or a high $\mathrm{CHO} /$ low fibre diet has a similar influence on the various metabolic variables considered in this study $\left(F_{2}\right)$ and that this influence is similar for patients with both types of diabetes $\left(\mathrm{F}_{1}\right)$. Moreover this type of analysis evaluates the possibility that there is interaction between the diets and the type of diabetes $\left(F_{3}\right)$.

\section{Results}

\section{Blood glucose control}

The influence of the three diets on blood glucose levels is shown in Figure 1. Fasting blood glucose did not show any significant modification during the three $\mathrm{di}-$ etary periods, with average concentrations of $6.9 \pm$ $2.5 \mathrm{mmol} / 1$ at the end of the low $\mathrm{CHO} /$ low fibre diet, $6.8 \pm 2.0 \mathrm{mmol} / \mathrm{l}$ after the high $\mathrm{CHO} /$ low fibre diet and $6.4 \pm 2.2 \mathrm{mmol} / \mathrm{l}$ after the high $\mathrm{CHO} /$ high fibre diet. The 2-h post-prandial blood glucose was significantly lower after the high $\mathrm{CHO} /$ high fibre diet $(6.8 \pm$ $2.7 \mathrm{mmol} / \mathrm{l}$ ) than after either the high $\mathrm{CHO} /$ low fibre $\operatorname{diet}(9.0 \pm 2.9 \mathrm{mmol} / \mathrm{l}, p<0.02)$ or the low $\mathrm{CHO} /$ low fi- 

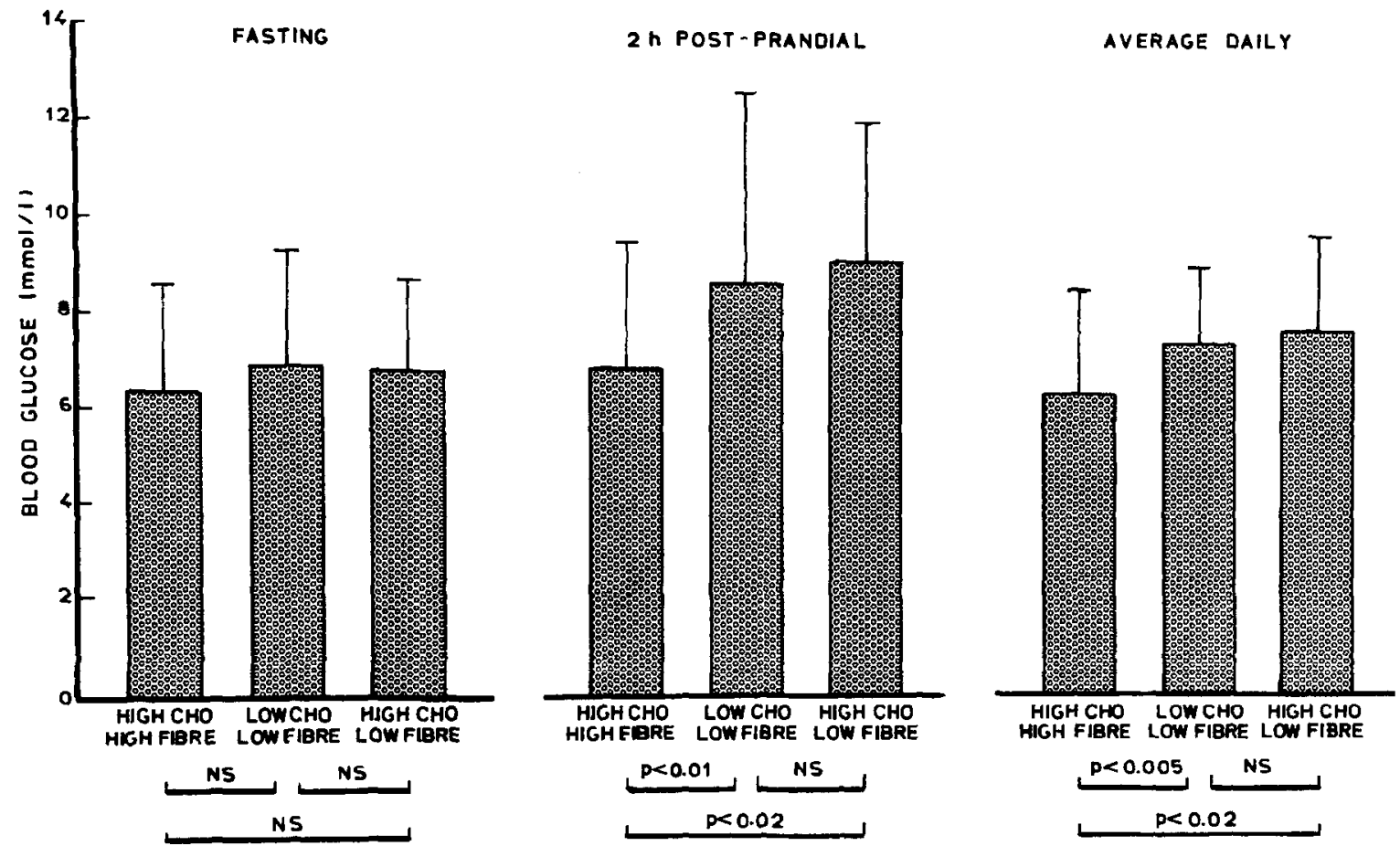

Fig. 1. Blood glucose control at the end of each dietary period. The bar indicates the average concentration + standard deviation for the whole group of patients

Table 3. Variations in blood glucose levels on changing from the low $\mathrm{CHO}$ /low fibre diet to either the high $\mathrm{CHO} /$ low fibre or to the high CHO/high fibre diet, evaluated for Type 1 and Type 2 diabetic patients

\begin{tabular}{lllll}
\hline Blood glucose (mmol/1) & \multicolumn{2}{l}{\begin{tabular}{l} 
Variations seen when changing diets \\
\cline { 2 - 5 }
\end{tabular}} & $\begin{array}{l}\text { Low CHO to } \\
\text { high CHO with } \\
\text { low fibre }\end{array}$ & $\begin{array}{l}\text { Low CHO to high } \\
\text { CHO + low fibre } \\
\text { to high fibre }\end{array}$ \\
\hline Fasting & Type 1 & $-0.38 \pm 4.97$ & $-2.09 \pm 1.83$ \\
& Type 2 & $1.19 \pm 2.57$ & $-0.17 \pm 1.18$ \\
& & $F_{1}=2.55 \quad F_{2}=1.98$ & $F_{3}=0.03$ \\
2-h Post-prandial & Type 1 & $-0.15 \pm 1.36$ & $-2.83 \pm 2.32$ \\
& Type 2 & $1.13 \pm 4.10$ & $-1.01 \pm 1.21$ \\
Average daily & & $F_{1}=2.09$ & $F_{2}=5.86^{b}$ & $F_{3}=0.07$ \\
& Type 1 & $-0.05 \pm 1.67$ & $-1.29 \pm 1.75$ \\
& Type 2 & $0.68 \pm 2.40$ & $-1.05 \pm 0.87$ \\
& & $F_{1}=0.52$ & $F_{2}=4.86^{\mathrm{a}}$ & $F_{3}=0.13$ \\
\hline
\end{tabular}

Results expressed as mean $\pm \mathrm{SD}$. Two way analysis of variance: $F_{1}=$ type of diabetes; $F_{2}=$ type of diet; $F_{3}=$ interaction. ${ }^{a} p<0.05$; ${ }^{\mathrm{b}} p<0.02$

bre diet $(8.7 \pm 3.9 \mathrm{mmol} / 1, p<0.01)$. No significant difference was found between the high $\mathrm{CHO} /$ low fibre and the low $\mathrm{CHO} /$ low fibre diet.

A similar pattern was seen in the average daily blood glucose which decreased after the high $\mathrm{CHO}$ / high fibre diet $(6.4 \pm 2.2 \mathrm{mmol} / \mathrm{l})$ compared with both the high $\mathrm{CHO} /$ low fibre diet $(7.8 \pm 2.0 \mathrm{mmol} / 1, p<$ $0.02)$ and the low $\mathrm{CHO} /$ low fibre $\operatorname{diet}(7.5 \pm 1.5 \mathrm{mmol} / \mathrm{l}$, $p<0.005$ ). Once again no significant change was recorded between the two low fibre diets with low or high $\mathrm{CHO}$ content.
Blood glucose level variations, observed when changing from the low $\mathrm{CHO} /$ low fibre diet to either the high $\mathrm{CHO} /$ low fibre diet or the high $\mathrm{CHO} /$ high fibre diet, were then evaluated for each patient and a twoway analysis of variance was performed (Table 3 ). This type of analysis was chosen in order to test whether the two high CHO diets, with different contents of vegetable fibre, had different influences on blood glucose parameters. At the same time, by this type of analysis it was possible to compare the effects of these diets in Type 1 diabetic patients with those obtained in Type 2 patients.

Fasting blood glucose was not significantly influenced by either the type of diabetes or the type of diet (Table 3).

In the group with Type 1 diabetes, the 2-h postprandial blood glucose concentration decreased by only $0.2 \pm 1.4 \mathrm{mmol} / 1$ after the high $\mathrm{CHO} /$ low fibre diet and by as much as $2.8 \pm 2.3 \mathrm{mmol} / 1$ after the high $\mathrm{CHO} /$ high fibre diet, by comparison with the low $\mathrm{CHO} /$ low fibre diet. In Type 2 diabetic patients the $2-\mathrm{h}$ post-prandial blood glucose concentration increased by $1.1 \pm 4.1 \mathrm{mmol} / 1$ after the high $\mathrm{CHO} /$ low fibre diet. Conversely it fell by $1.0 \pm 1.2 \mathrm{mmol} / 1$ after the high $\mathrm{CHO} /$ high fibre diet. The type of dietary treatment $\left(\mathrm{F}_{2}=5.86, p<0.02\right)$ but not the type of diabetes $\left(\mathrm{F}_{1}=2.09\right)$ had a significant influence on this parameter. No interaction between diets and type of disease $\left(F_{3}=0.07\right)$ was statistically significant (Table 3$)$.

The average daily blood glucose concentration showed a similar pattern. In Type 1 patients it showed a slight decrease after the high $\mathrm{CHO} /$ low fibre diet 

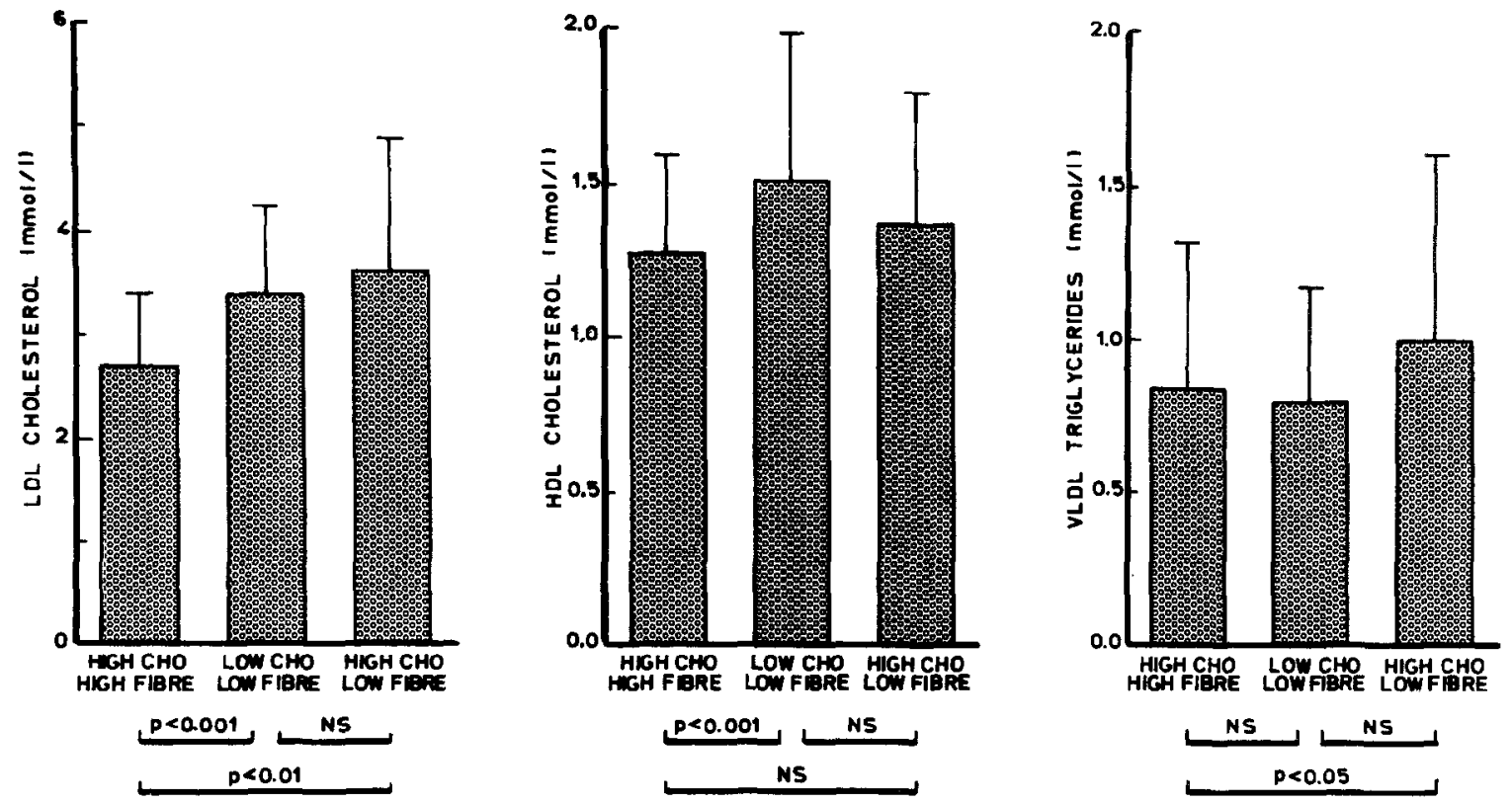

Fig. 2. Composition of the major lipoprotein classes at the end of each dietary period. The bar indicates the average concentration + standard deviation for the whole group of patients

$(-0.1 \pm 1.7 \mathrm{mmol} / \mathrm{l})$ and a more pronounced reduction after the high $\mathrm{CHO} /$ high fibre diet compared with the low $\mathrm{CHO} /$ low fibre diet $(-1.3 \pm 1.7 \mathrm{mmol} / \mathrm{l})$. In Type 2 patients the average daily blood glucose increased by $0.7 \pm 2.4 \mathrm{mmol} / 1$ after the high $\mathrm{CHO} /$ low fibre diet. It decreased, instead, by $1.1 \pm 0.9 \mathrm{mmol} / \mathrm{l}$ after the high $\mathrm{CHO} /$ high fibre diet. Once again only the type of diet $\left(F_{2}=4.86, p<0.05\right)$ was related to this parameter (Table 3).

\section{Serum lipoproteins}

In Figure 2 the concentrations of the major serum lipoproteins are shown after each dietary period (available for six Type 2 and five Type 1 patients).

The LDL cholesterol concentration was significantly lower after the high $\mathrm{CHO} /$ high fibre diet $(2.8 \pm$ $0.7 \mathrm{mmol} / 1$ ) than after the low $\mathrm{CHO} /$ low fibre diet $(3.6 \pm 0.8 \mathrm{mmol} / 1, p<0.001)$ or the high $\mathrm{CHO} /$ low fibre diet $(3.8 \pm 1.3 \mathrm{mmol} / 1, p<0.01)$. No significant difference was found between the two low fibre diets with different amounts of CHO. Total serum cholesterol levels behaved in a similar way. The concentration fell to $4.7 \pm 0.7 \mathrm{mmol} / 1$ after the high $\mathrm{CHO} /$ high fibre diet, from $5.6 \pm 0.9 \mathrm{mmol} / \mathrm{l}$ after the low $\mathrm{CHO} /$ low fibre diet $(p<0.001)$ or $5.9 \pm 1.3 \mathrm{mmol} / \mathrm{l}$ after the high $\mathrm{CHO} / \mathrm{low}$ fibre diet $(p<0.01)$. The difference between the two low fibre diets was not significant.

The high-density lipoprotein (HDL) cholesterol was also reduced after the high $\mathrm{CHO} /$ high fibre diet compared with the low $\mathrm{CHO} /$ low fibre diet $(1.3 \pm 0.3$ versus $1.5 \pm 0.4 \mathrm{mmol} / 1, \mathrm{p}<0.005$ ). After the high $\mathrm{CHO} / \mathrm{low}$ fibre diet the HDL cholesterol concentration of $1.4 \pm$ $0.4 \mathrm{mmol} / 1$ was not significantly different from the other two diets.
No significant differences between the three diets were found in the concentrations of total serum triglycerides. The triglyceride composition of the very-lowdensity lipoprotein class (VLDL) was instead significantly reduced after the high $\mathrm{CHO} /$ high fibre diet compared with the high $\mathrm{CHO} /$ low fibre diet $(0.9 \pm 0.5$ versus $1.1 \pm 0.6 \mathrm{mmol} / 1, p<0.05$ ). The VLDL triglyceride concentration after the low $\mathrm{CHO} /$ low fibre diet $(0.8 \pm 0.3 \mathrm{mmol} / 1)$ was not significantly different from that found after the other two diets.

The ratio VLDL + LDL/HDL cholesterol was lower after the high $\mathrm{CHO} /$ high fibre $\operatorname{diet}(2.6 \pm 1.2)$ than after the high $\mathrm{CHO} /$ low fibre diet $(3.5 \pm 1.5, p<0.02)$ or the low $\mathrm{CHO} /$ low fibre diet $(2.9 \pm 1.2)$. In the latter case the difference did not reach statistical significance. The comparison between the high $\mathrm{CHO} /$ low fibre and the low $\mathrm{CHO} /$ low fibre diet showed a difference which was significant at the $5 \%$ level.

The influence of the two high CHO diets and of both types of diabetes on the composition of the major serum lipoproteins was then checked by two-way analysis of variance performed on the variations between the concentration of serum lipoproteins after each of the two high $\mathrm{CHO}$ diets and that found at the end of the low CHO diet (Table 4).

A significant influence of the type of dietary treatment $\left(F_{2}=10.02, p<0.005\right)$ was found only for $\mathrm{LDL}$ cholesterol and not for HDL cholesterol or VLDL triglycerides. Conversely a significant influence of the type of diabetes was found for VLDL triglycerides $\left(\mathrm{F}_{1}=6.55, p<0.02\right)$.

\section{Body weight}

Despite the fact that the three diets were designed to keep body weight constant, a slight but significant in- 
Table 4. Variations in serum lipoprotein composition changing from the low $\mathrm{CHO} /$ low fibre diet to either the high $\mathrm{CHO} /$ low fibre or to the high $\mathrm{CHO} /$ high fibre diet, evaluated for Type 1 and Type 2 diabetic patients

\begin{tabular}{|c|c|c|c|c|}
\hline \multirow{2}{*}{\multicolumn{2}{|c|}{ Lipoproteins (mmol/1) }} & \multicolumn{3}{|c|}{ Variations seen when changing diet } \\
\hline & & $\begin{array}{l}\text { Low CHO to } \\
\text { high CHO with } \\
\text { low fibre }\end{array}$ & \multicolumn{2}{|c|}{$\begin{array}{l}\text { Low CHO to high } \\
\mathrm{CHO}+\text { low fibre } \\
\text { to high fibre }\end{array}$} \\
\hline LDL Cholesterol & $\begin{array}{l}\text { Type } 1 \\
\text { Type } 2\end{array}$ & $\begin{array}{c}0.35 \pm 0.65 \\
0.17 \pm 0.99 \\
F_{1}=0.14 \quad F_{2}=\end{array}$ & $0.02^{\mathrm{b}}$ & $\begin{array}{l}-0.68 \pm 0.66 \\
-0.73 \pm 0.38 \\
F_{3}=0.04\end{array}$ \\
\hline HDL Cholesterol & $\begin{array}{l}\text { Type } 1 \\
\text { Type } 2\end{array}$ & $\begin{array}{l}-0.16 \pm 0.29 \\
-0.09 \pm 0.29 \\
F_{1}=0.21 \quad F_{2}\end{array}$ & & $\begin{array}{l}-0.23 \pm 0.18 \\
-0.22 \pm 0.15 \\
F_{3}=0.11\end{array}$ \\
\hline VLDL Triglycerides & $\begin{array}{l}\text { Type } 1 \\
\text { Type } 2\end{array}$ & $\begin{array}{c}-0.02 \pm 0.29 \\
0.90 \pm 1.10 \\
F_{1}=6.55^{\mathrm{a}} \quad F_{2}\end{array}$ & & $\begin{aligned}-0.28 \pm 0.45 \\
0.42 \pm 0.74 \\
\mathrm{~F}_{3}=0.12\end{aligned}$ \\
\hline
\end{tabular}

Results expressed as mean $\pm \mathrm{SD}$. Two way analysis of variance: $F_{1}=$ type of diabetes; $F_{2}=$ type of diet; $F_{3}=$ interaction. ${ }^{a} p<0.02$; ${ }^{\mathrm{b}} p<0.005$

crease in body weight was observed at the end of the high $\mathrm{CHO} /$ high fibre diet $(64.4 \pm 11.6 \mathrm{~kg})$ compared with the low $\mathrm{CHO} /$ low fibre diet $(64.0 \pm 11.5 \mathrm{~kg}, p<$ 0.02 ). No significant difference was found after the high $\mathrm{CHO} /$ low fibre $\operatorname{diet}(64.2 \pm 11.6 \mathrm{~kg})$.

\section{Treatment}

Although Type 2 diabetic patients did not have to modify their drug treatment during the study, four out of six Type 1 patients had to reduce their insulin dosage by an average of 4 units/day during the high $\mathrm{CHO} /$ high fibre diet in order to avoid severe hypoglycaemic attacks.

\section{Discussion}

The results of this study clearly demonstrate that a simple increase of digestible CHO (up to $53 \%$ of the daily caloric intake) gives no benefit at all in terms of blood glucose control, compared with the traditional low fibre $(20 \mathrm{~g}) /$ low $\mathrm{CHO}(42 \%)$ diet (still used in many countries). Instead, parallel increases of dietary CHO (53\%) and fibre $(54 \mathrm{~g})$ produced a significant improvement in blood glucose control, whether evaluated as postprandial blood glucose or as daily blood glucose profile (Fig.1). Furthermore the high $\mathrm{CHO} /$ high fibre diet is equally effective in both Type 1 and Type 2 patients (Table 3).

Other groups have compared a high $\mathrm{CHO} /$ high fibre diet with a traditional low $\mathrm{CHO} /$ low fibre diet, obtaining a substantial improvement in blood glucose control with the former diet $[19,20]$. This positive effect on blood glucose control was ascribed both to the high level of dietary CHO and to vegetable fibre. Our findings clearly demonstrate that increasing the amount of $\mathrm{CHO}$ in the diet from 240 to $320 \mathrm{~g} /$ day has very little influence on fasting blood glucose concentrations and, if anything, contributes to the deterioration of blood glucose control in the post-prandial phase.

An increase in the amount of fibre in the diet is more important for diabetic patients. We have shown in this study (Fig.1), confirming our previous findings, that dietary fibre, per se, can reduce blood glucose concentrations in diabetic patients [9]. Therefore any positive effect of a high $\mathrm{CHO} /$ high fibre diet on blood glucose control in diabetes has to be ascribed mainly to the high level of dietary fibre.

A diet for the treatment of diabetic patients has to be judged not only for its effects on blood glucose control but also for its influence on atherogenesis and on the major risk factors for atherosclerosis, such as lipids and lipoproteins. Unfortunately, because of the experimental design of this study, only short-term lipoprotein results are available. Therefore further studies with longer follow-up periods are needed before drawing more definitive conclusions on the influence of dietary fibre on serum lipoprotein composition.

A simple increase of dietary $\mathrm{CHO}$ without changes in vegetable fibre did not modify LDL cholesterol concentrations in all the patients (Fig. 2) to any significant extent. This finding was not unexpected even if $\mathrm{CHO}$ replaced the lipids in the high $\mathrm{CHO} /$ low fibre diet. Any variation in dietary lipids was obtained keeping constant the ratio between poliunsaturated and saturated fats. It is well known that changes in the amount of dietary fats have little effect on serum lipoprotein composition, if this ratio is kept constant [21].

Dietary fibre had a more pronounced effect than $\mathrm{CHO}$ on the LDL lipoprotein fraction. A significant reduction of LDL cholesterol was, in fact, recorded after the high $\mathrm{CHO} /$ high fibre diet (Fig. 2). This was of the same order of magnitude in both types of diabetes (Table 4). A similar finding was found with a high fibre diet in patients with Type II hyperlipoproteinaemia without diabetes [22].

HDL cholesterol was higher after the low $\mathrm{CHO}$ diet than after either of the two high $\mathrm{CHO}$ diets, the difference being significant only for the high $\mathrm{CHO} /$ high fibre $\operatorname{diet}$ (Fig. 2). The two-way analysis of variance, however, did not show any significant difference between the effects of the two high CHO diets on HDL (Table 4), thus suggesting that a low dietary $\mathrm{CHO}$ level rather than a low amount of dietary fibre might be able to increase the HDL cholesterol concentration in diabetes. This is confirmed by a recent study by Simpson et al. in which HDL levels were higher after a simple reduction of dietary $\mathrm{CHO}$ without any modification of dietary fibre [23]. These changes in HDL cholesterol reflect, in part, parallel modifications in LDL cholesterol concentrations [24] and are probably transient [25, 26]. The VLDL + LDL/HDL cholesterol ratio, a feature of the lipoprotein pattern commonly considered an index of potential atherogenicity, was significantly reduced after the high $\mathrm{CHO} /$ high fibre diet compared with the high $\mathrm{CHO} /$ low fibre diet. 
In Type 2 patients VLDL triglyceride concentrations increased after changing from the low $\mathrm{CHO}$ diet to either of the two high CHO diets, as shown by analysis of variance (Table 4). This suggests that the mechanism of the CHO-induced hyper-VLDL triglyceridaemia is working only in Type 2 patients in whom dietary $\mathrm{CHO}$ can produce endogenous hyperinsulinism [27, 28] which, in turn, is responsible for accelerating VLDL synthesis $[29,30]$. However, dietary fibre can influence VLDL metabolism, reducing VLDL triglyceride concentration (Fig. 2).

In conclusion, increasing the $\mathrm{CHO}$ consumption in the diabetic diet gives no benefit in terms of blood glucose control or serum lipoprotein composition. Conversely, increasing at the same time both dietary $\mathrm{CHO}$ and fibre improves blood glucose control and reduces LDL cholesterol together with HDL cholesterol. Therefore, according to the present evidence, an increase of available CHO is justified for the dietary treatment of patients with diabetes only when dietary fibres are increased in a parallel fashion. The type of diet we have used (high in fibre and with a moderate amount of $\mathrm{CHO}$ ) seems to have the therapeutical properties to justify a trial on a larger scale. Moreover, it is composed only of natural food stuffs and is designed to resemble closely the type of diet used in Mediterranean countries a few decades ago.

Acknowledgements. We gratefully acknowledge the cooperation of Mr. A. Gurrieri - the cook of the metabolic unit. This study was supported by Cilag Foundation for Therapeutic Research. This paper was presented, in part, at the 18th Annual Meeting of the EASD.

\section{References}

1. American Diabetes Association (1979) Principles of nutrition and dietary recommendations for individuals with diabetes. Diabetes Care 2: 520-523

2. British Diabetic Association (1982) Dietary recommendations for diabetics for the 1980's. Hum Nutr Appl Nutr 36 A: 378-394

3. Special Report Committee (1981) Guidelines for the nutritional management of diabetes mellitus: A special report from the Canadian Diabetes Association. J Can Dietet Assoc 42: 110-118

4. Reaven GM (1980) How high the carbohydrate? Diabetologia 19: 409-413

5. Brunzell JD, Lerner RL, Hazzard WR, Porte D jr, Bierman EL (1971) Improved glucose tolerance with high carbohydrate feeding in mild diabetes. N Engl J Med 284: 521-524

6. Brunzell JD, Lerner RL, Porte D jr, Bierman EL (1979) Effect of a fat free high carbohydrate diet on diabetic subjects with fasting hyperglycemia. Diabetes 23: 138-142

7. Weiser RL, Seeman A, Herrera G, Assal GP, Soeldner JS, Gleason RE (1974) High and low carbohydrate diets in diabetes mellitus: study of effects on diabetic control, insulin secretion and blood lipids. Ann Intern Med 8: 332-341

8. Kjehm TG, Anderson JW, Ward K (1976) Beneficial effects of a high carbohydrate, high fibre diet on hyperglycemic diabetic men. Am J Clin Nutr 29: 895-899

9. Rivellese A, Riccardi G, Giacco A, Pacioni D, Genovese S, Mattioli PL, Mancini M (1980) Effect of dietary fibre on glucose control and serum lipoproteins in diabetic patients. Lancet 2: 447-450

10. Rivellese A, Riccardi G, Giacco A, Pacioni D, Genovese S, Mattioli PL, Mancini M (1981) A fibre rich diet for the treatment of diabetes. In: Howard AN, McLean Baird I (eds) Recent advances in clinical nutrition I. J Libbey, London, pp 99-100
11. Jenswell AS, Thomas BJ, Brown AM (1975) Survey of dietary policy and management in British diabetic clinics. Br Med J 2: 7-11

12. Fidanza F, Versiglione $N(1982)$ Tabelle di composizione degli alimenti. Idelson, Napoli

13. Southgate DAT (1969) Determination of carbohydrates in foods. II. Unavailable carbohydrates. J Sci Food Agric 20: 331-335

14. Hjelm M (1966) Enzymatic determination of hexoses in blood and urine Scand. J Clin Lab Invest 18: (Suppl 192): 85-89

15. Klose S, Hagen A, Greif H (1975) Mèthode de dosage colorimétrique du cholestérol par voie entièrement enzymatique adaptée à tous les types de auto-analyseur. In: Biologie prospective, 111. Colloque de Pont-à-Mousson. L'Expansion Scientifique Française, Paris. pp 505-537

16. Wahlefeld AN (1974) Triglycerides determination after enzymatic hydrolysis. In: Bergmeyer HV (ed) Methods of enzymatic analysis, Academic Press, New York

17. Carlson K (1973) Lipoprotein fractionation. J Clin Path 26 (Suppl 5): 32

18. Snedecor GW, Cochran WH (1967) Statistical Methods. Ames Iowa USA

19. Simpson HCR, Simpson RW, Lousley S, Carter RD, Gekh M, Hockaday JDR, Mann JI (1981) A high carbohydrate leguminous fibre diet improves all aspects of diabetic control. Lancet 2: 1-5

20. Anderson JW, Kyllen W (1979) High carbohydrate-high fiber diets for insulin treated men with diabets mellitus. Am $\mathbf{J}$ Clin Nutr 2: 2312-2321

21. Report of a WHO Expert Committee (1982) Prevention of coronary heart disease. Technical Report series 678. WHO, Geneva

22. Rivellese A, Riccardi G, Giacco A, Postiglione A, Mastranzo P, Mattioli PL (1983) Reduction of risk factors for atherosclerosis in diabetic patients treated with a high fiber diet. Prev Med 12: $128-132$

23. Simpson HCR, Carter RD, Lousley S, Mann JI (1982) Digestible carbohydrate - an independent effect on diabetic control in Type 2 (non-insulin-dependent) diabetic patients? Diabetologia 23: $235-239$

24. Riccardi G, Rivellese A, Romano G, Giacco R, Mancini M (1984) The influence of dietary fibre on serum lipoproteins in diabetic and hyperlipidaemic patients In: Carlson LA, Olsson AC (eds) Treatment of hyperlipoproteinaemia. Raven Press, New York (in press)

25. Jenkins DJA, Reynolds D, Slavin B, Leeds AR, Jenkins AL, Jepson EM (1980) Dietary fiber and blood lipids: treatment of hypercholesterolemia with guar crispbread. Am J Clin Nutr 33: 575-581

26. Taskinen M, Nikkilä EA, Ollus A (1983) Serum lipids and lipoproteins in insulin-dependent diabetic subjects during high-carbohydrate, high-fiber diet. Diabetes Care 6: 224-230

27. Greenfield M, Koltermann O, Olefsky J, Reaven GM (1980) Mechanism of hypertriglyceridaemia in diabetic patients with fasting hyperglycaemia. Diabetologia 18: 441-446

28. Farquhar JW, Frank A, Gross RC, Reaven GM (1966) Glucose, insulin and triglyceride responses to high and low carbohydrate diets in man. J Clin Invest 45: 1641-1656

29. Rivellese A, Riccardi G, Farinaro E, Capaldo B, Mancini M (1978) Relationship between insulin response to intravenous glucose and VLDL triglycerides in a healthy population. Diabetes and obesity. In: Vague J, Vague $\mathrm{Ph}$ (eds) Proceedings of the Vth International Meeting of Endocrinology. Excerpta Medica, Amsterdam, Oxford, pp 303-306

30. Olefsky MJ, Farquhar JW, Reaven GM (1974) Reappraisal of the role of insulin in hypertriglyceridemia. Am J Med 57: 552-560

Received: 21 February 1983

and in revised form: 8 September 1983

Dr. G. Riccardi

Clinica Medica 2

2 Facoltà di Medicina e Chirurgia

Nuovo Policlinico

Via S. Pansini, 5

I-80131 Naples, Italy 